\title{
Peptide-modified Microelectrode-based Potentiometric Device for 2,4,6-trinitrotoluene Molecule Detection
}

\author{
Jin Wang, ${ }^{1 *}$ Rui Yatabe, ${ }^{1,2}$ Takeshi Onodera, ${ }^{2}$ \\ Masayoshi Tanaka, ${ }^{3}$ Mina Okochi, ${ }^{3}$ and Kiyoshi Toko ${ }^{1,4}$ \\ ${ }^{1}$ Research and Development Center for Five-Sense Devices, \\ Kyushu University, 744 Motooka, Nishiku, Fukuoka 819-0395, Japan \\ ${ }^{2}$ Department of Information Science and Electrical Engineering, \\ Kyushu University, 744 Motooka, Nishiku, Fukuoka 819-0395, Japan \\ ${ }^{3}$ Department of Chemical Science and Engineering, Tokyo Institute of Technology, \\ 2-12-1 O-Okayama, Meguro-ku, Tokyo 152-8552, Japan \\ ${ }^{4}$ Institute for Advanced Study, Kyushu University, \\ 744 Motooka, Nishiku, Fukuoka 819-0395, Japan \\ (Received March 27, 2019; accepted July 8, 2019)
}

Keywords: recognition peptide TNTHCDR3, potentiometric device, change in potential

A 2,4,6-trinitrotoluene (TNT) molecule recognition peptide-modified potentiometric device was developed in a multiparallel way using microelectrodes. The change in potential caused by the explosive target and recognition peptide was monitored in real-time sensorgrams through our laboratory-built analysis system. The peptide-modified microelectrode-based potentiometric device demonstrated the highly selective and sensitive sensing of the TNT molecule over other aromatic analogues.

\section{Introduction}

Electrical sensing has been widely used for the detection of heavy metal ions, proteins, DNA, and some hazardous molecules. ${ }^{(1-6)}$ In particular, the development of electrical sensing devices for detecting hazardous explosive molecules has been rapid since such molecules have become a major threat to global security and also an important environmental issue because of the contamination of agricultural land and products and the threat to normal life. ${ }^{(7)}$ To date, great progress has been made, and devices such as quartz crystal microbalance (QCM) and techniques including square wave voltammetry (SWV), electrochemical impedance spectroscopy (EIS), and colorimetric method have been used for the detection of nitroaromatic compounds in both liquid and vapor phases. ${ }^{(8-12)}$ In particular, field-effect transistor (FET)based biosensors have been considered in the detection of nitrates and some small molecules because of their easy integration, low cost, and high throughput with the target receptor functionalized on the semiconducting layers. ${ }^{(2,4,5)}$ FET-based potentiometric biosensing detects the concentration of biomolecules captured on a semiconducting gate electrode, where the charged biomolecules change the carrier concentration. ${ }^{(2,13)}$ An extended gate-FET has been *Corresponding author: e-mail: wang.jin.335@m.kyushu-u.ac.jp https://doi.org/10.18494/SAM.2019.2385 
successfully fabricated for the detection of protein biomolecules (e.g., lysozyme and thrombin) and the influenza virus, realizing a platform for a simple and rapid diagnostic system by measuring the change in potential. ${ }^{(14-17)}$ Therefore, potentiometric biosensing methods are promising for various applications in the near future.

In this study, a newly fabricated 2,4,6-trinitrotoluene (TNT) recognition peptide TNTHCDR3-modified microelectrode-based potentiometric device was used for the rapid, specific, and real-time detection of TNT molecules. The TNT recognition peptide was synthesized in accordance with our previous work. ${ }^{(18,19)}$ The mechanism for TNT explosive detection is based on the change in potential, which is mainly caused by the charge transfer between the positively charged group in TNT molecules and the negatively charged TNTHCDR3 peptide during the binding interaction. The sensitivity, selectivity, and stability of the peptide-based potentiometric device were investigated to evaluate its performance.

\section{Experimental Procedure}

The details of the microelectrode-based potentiometric device fabrication procedure were described in a previous work. ${ }^{(16)}$ Briefly, 10 disc-shaped gold microelectrodes $(500 \mu \mathrm{m}$ in diameter) were connected to an electrometer/high-resistance meter (Keithley, Cleveland, $\mathrm{OH}$ ) to monitor the change in voltage. The measurement system is illustrated in Figs. 1(a) and 1(b). The flow system measurement procedure is described as follows. The potentiometric sensor chip was firstly anchored to the sensing unit and placed in an incubator with the temperature fixed at $25{ }^{\circ} \mathrm{C}$ to prevent interference from the environment. Then, the explosive sample ( $250 \mu \mathrm{L}$ for each measurement) was injected into the flow system through the sample injector and pumped to pass it through the microelectrode area (sensing unit) where the explosive recognition peptide was covalently immobilized on the surface. The system running buffer, $0.01 \mathrm{M}$ phosphatebuffered saline (PBS, $0.138 \mathrm{M} \mathrm{NaCI}, 0.0027 \mathrm{M} \mathrm{KCI}, \mathrm{pH}$ 7.4) containing 0.05\%Tween $20(\mathrm{~T})$ and $5 \%$ DMF ( $N, N$-dimethylformamide) (PBST in 5\% DMF), with a nitrogen flow was chosen to stabilize the flow system (flow rate: $500 \mu \mathrm{L} / \mathrm{min}$ ) to prevent environmental interference. When the explosive sample arrived at the microelectrode area, the change in electrical potential at the microelectrode was monitored using our laboratory-built data analysis system. After the reaction, the sample was pushed out by running buffer to a waste well. Each measurement cycle (reaction time of $400 \mathrm{~s}$ ) started when the explosive samples began to react with the peptidebased gold surface and ended when the electrical potential returned to the baseline.

The preparation and characterization of the sensor chip surface are shown in Fig. 1(c) and described as follows. The PEG6-COOH aromatic dialkanethiol selected as a self-assembled monolayer (SAM) reacted with the gold surface through the formation of a strong $\mathrm{Au}-\mathrm{S}$ bond similarly in our previous studies. ${ }^{(20,21)}$ Wettability measurements showed that the water contact angle changed $\left(61.0 \pm 1.0^{\circ}\right.$ to $\left.35.2 \pm 0.9^{\circ}\right)$ as a result of SAM treatment. The SAM on each microelectrode was formed by immersing the potentiometric device chip in $1 \mathrm{mM}$ PEG6$\mathrm{COOH}$ aromatic dialkanethiol overnight. The surface was rinsed with ethanol and Milli-Q water at least three times. Then, a mixture solution of 1-ethyl-3-(3-dimenthylaminopropyl) carbodiimide (EDC) and $\mathrm{N}$-hydroxy succinimide (NHS) was added to activate and convert 

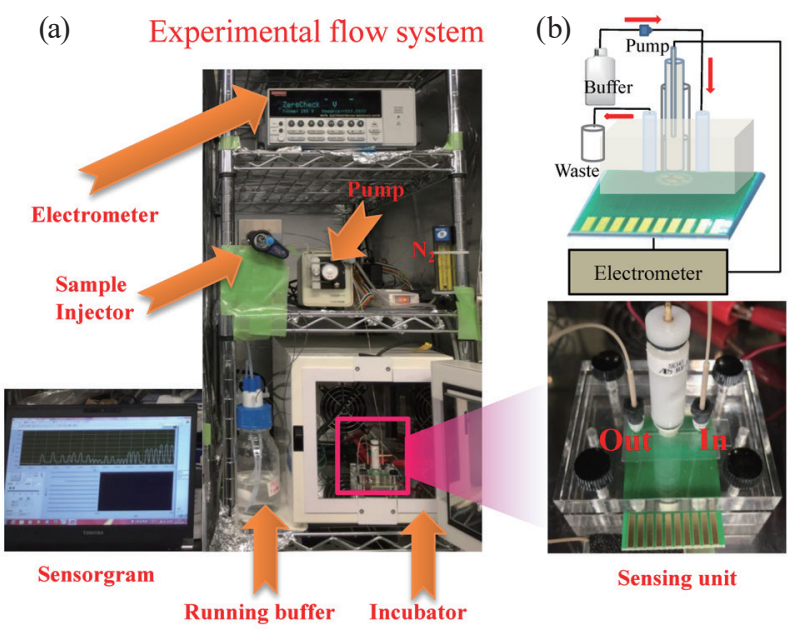

(c)

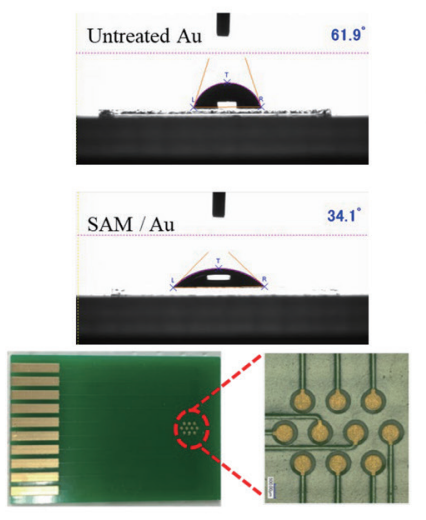

(d)
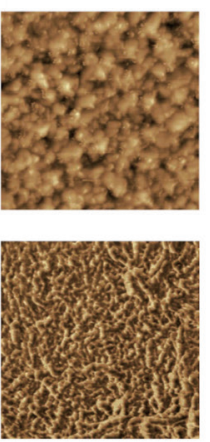

(e)
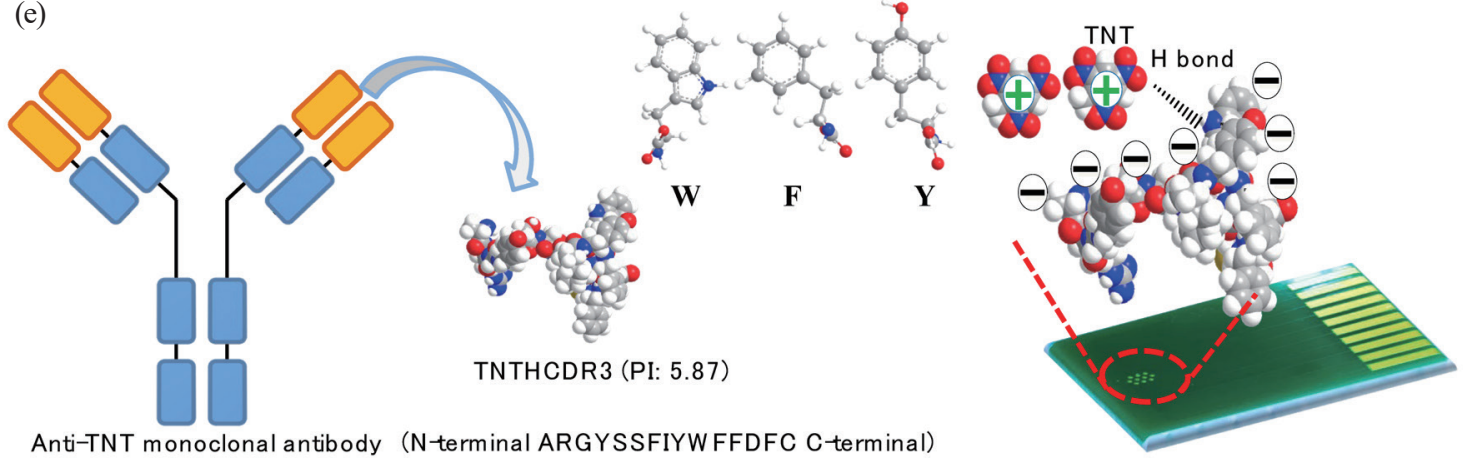

Fig. 1. (Color online) (a) Schematic representation of the experimental flow system for the TNT detection in solution. (b) Diagram of the potentiometric device for TNT sensing. (c) Representation of the TNT recognition peptide-functionalized potentiometric device and wettability measurements before and after SAM treatment. (d) AFM image of sensor chip functionalized with/without TNTHCDR3 peptide (upper: surface without peptide; lower: surface with peptide). (e) Schematic representation of the TNTHCDR3 binding peptide derived from the anti-TNT monoclonal antibody and the mechanism of binding to the TNT molecule.

the carboxyl terminal groups to NHS esters. In accordance with a previous study, the 15-mer amino acid sequence (ARGYSSFIYWFFDFC) obtained from the complementarity-determining region heavy chain (HCDR) in the anti-TNT monoclonal antibody was determined as the TNT recognition peptide (named TNTHCDR3), whereas the TNTLCDR3 (sequence: CLQHYSAPYTC) peptide derived from the light chain of the complementarity-determining region (LCDR) in the anti-TNT monoclonal antibody was demonstrated to show no appreciable binding to the TNT explosive. ${ }^{(18)} 1000$ ppm TNT recognition peptide was immobilized through the amine coupling method to obtain the highest surface density for TNT binding, which was followed by blocking with ethanolamine solution. The surface morphology with/without the anchored peptide was evaluated by atomic force microscopy (AFM) as shown in Fig. 1(d). A control experiment was 
performed by immobilizing the control peptide TNTLCDR3 on the gold surface by the same method. 1.9, 15.7, 31.4, 62.7, 125.4, and 250.8 ppm TNT solutions were prepared in PBST-5\% DMF buffer solution, each of which was injected into the flow system three times to perform three cycles of measurements. The change in potential was recorded when TNT molecules were captured by the recognition peptide in real time. The sensor surface was regenerated to the baseline potential by running buffer (PBST-5\% DMF) after each measurement.

\section{Results and Discussion}

The results in Figs. 2(a) and 2(b) show a strong linear relationship between the change in potential and the concentration (1.9 to $62.7 \mathrm{ppm}$ with correlation coefficient $\left.R^{2}=0.9900\right)$ of TNT samples. The sensor started to saturate at a concentration higher than $62.7 \mathrm{ppm}$ according

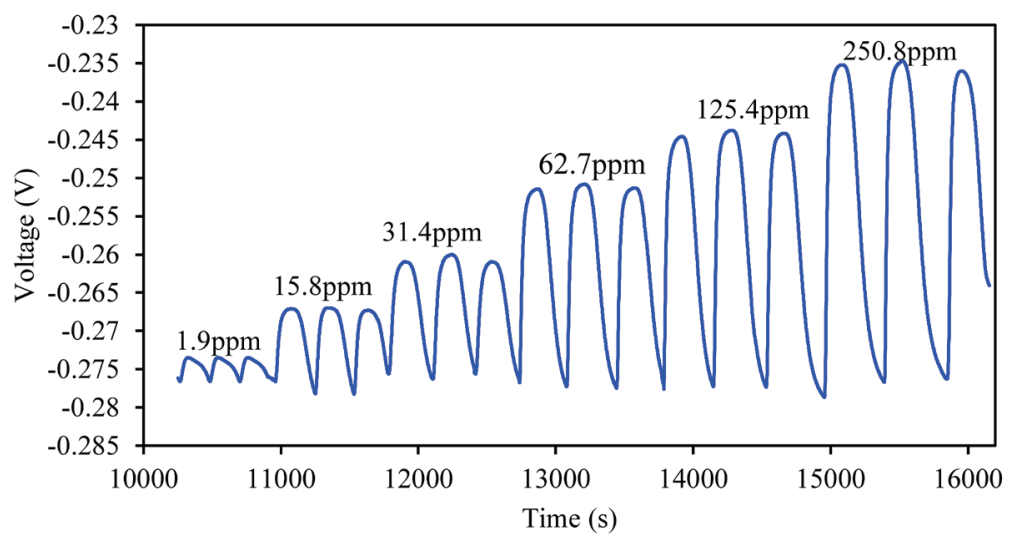

(a)

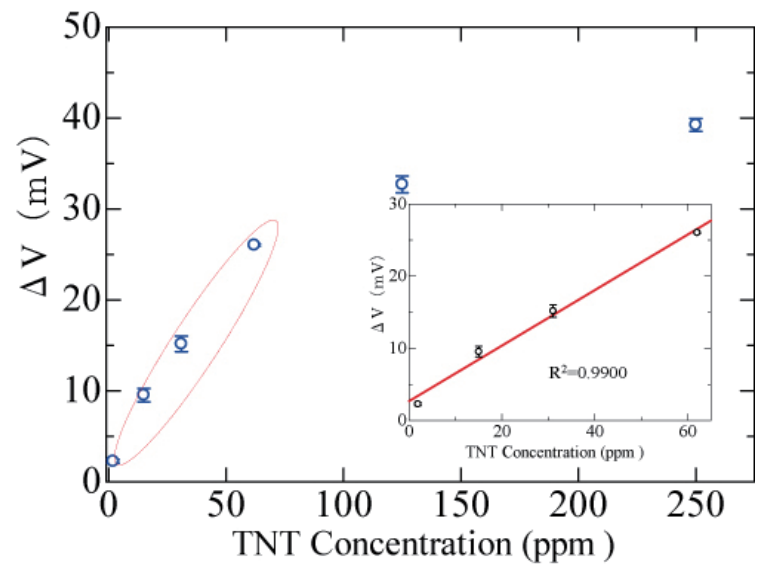

(b)

Fig. 2. (Color online) (a) Real-time sensorgram obtained from potentiometric device chip immobilized with TNT recognition peptide (TNTHCDR3). (b) Plot of the changes in potential corresponding to the various TNT concentrations obtained with real-time measurement sensorgram. Error bars indicate the calculated standard deviation $(n=3)$. 
to the curve. The limit of detection (LOD) was calculated to be $600 \mathrm{ppb}$ ( $3 \sigma$ in background solution). Table 1 shows the results of various studies of using different peptides as TNT receptors for sensitive and selective detection. A higher sensitivity was obtained in the present work than in our previous studies using the same peptide-based surface plasmon resonance (SPR) sensor as well as similar sensitivity to other reported methods. The results in Fig. 3 show the changes in the potentials of a TNTLCDR3-functionalized potentiometric chip and a TNTHCDR3-functionalized chip for TNT solutions with concentrations of 250.8 and 501.5 ppm. The TNTLCDR3-anchored potentiometric device exhibited a negligible response (equal to the background response) for both TNT concentrations, whereas the TNTHCDR3 peptideanchored chip exhibited a significantly greater response than the control chip. Therefore, the interaction mechanism between the TNT molecule and the TNTHCDR3 recognition peptide

Table 1

Peptide-functionalized sensors used for TNT detection.

\begin{tabular}{|c|c|c|c|c|}
\hline Peptide & Sensing device & Phase & LOD & Reference \\
\hline Polymer-oligopeptide & QCM & Liquid & Not mentioned & 8 \\
\hline VLP-bp-TNT & SWV & Liquid & $4 \mathrm{ppm}$ & 9 \\
\hline WHW & Colorimetric sensor & Gas & $300 \mathrm{ppb}$ & 11 \\
\hline ARGYSSFIYWFFDFC & SPR (CM 7 chip) & Liquid & $3.4 \mathrm{ppm}$ & 19 \\
\hline WHWQRPLMPVS & EIS & Liquid & $227 \mathrm{ppb}$ & 26 \\
\hline $\begin{array}{l}\text { CGGGGGGGGGGG } \\
\text {-WHWQRPLMPVSI }\end{array}$ & $\begin{array}{l}\text { Surface-enhanced Raman } \\
\text { scattering (SERS) }\end{array}$ & Liquid & $22.7 \mathrm{ppb}$ & 27 \\
\hline ARGYSSFIYWFFDFC & APTES-based SPR & Liquid & $1.35 \mathrm{ppm}$ & 28 \\
\hline ARGYSSFIYWFFDFC & $\begin{array}{l}\text { Single-walled carbon } \\
\text { nanotube-based SPR }\end{array}$ & Liquid & $772 \mathrm{ppb}$ & 29 \\
\hline ARGYSSFIYWFFDFC & Potentiometric sensing & Liquid & $600 \mathrm{ppb}$ & This work \\
\hline
\end{tabular}

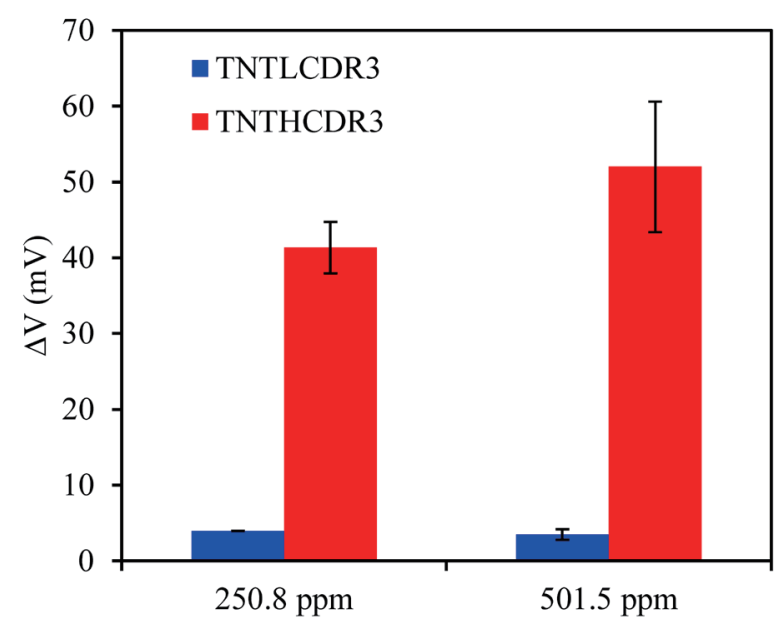

Fig. 3. (Color online) Responses of potentiometric device chip immobilized with TNT recognition peptide (TNTHCDR3) and control sensor chip with TNTLCDR3. 
was investigated. In previous studies, a computational model predicted that the TNT molecule binds to the peptide named antennal specific protein-1 (P1ASP1) from the honeybee through a hydrogen bond with tryptophan $\left(\operatorname{Trp}^{17}\right)$ amino acid $(\mathrm{W})$ and to a single-walled carbon nanotube (SWCNT) through $\pi-\pi$ interaction on the surface. The sequence Trp-Phe-Val-Ile (WFVI) in P1ASP1 at the C-terminal plays an important role in the reaction with the TNT molecule. ${ }^{(10)}$ The highly stable polymer structures designed to recognize TNT exhibited the shape and electrostatic complementarity between the negatively charged region of triphenylene and the positively charged region of TNT, where electrostatic potentials were calculated. ${ }^{(22)}$ As a commonly accepted mechanism, the aromatic rings of TNT are electron-deficient, which

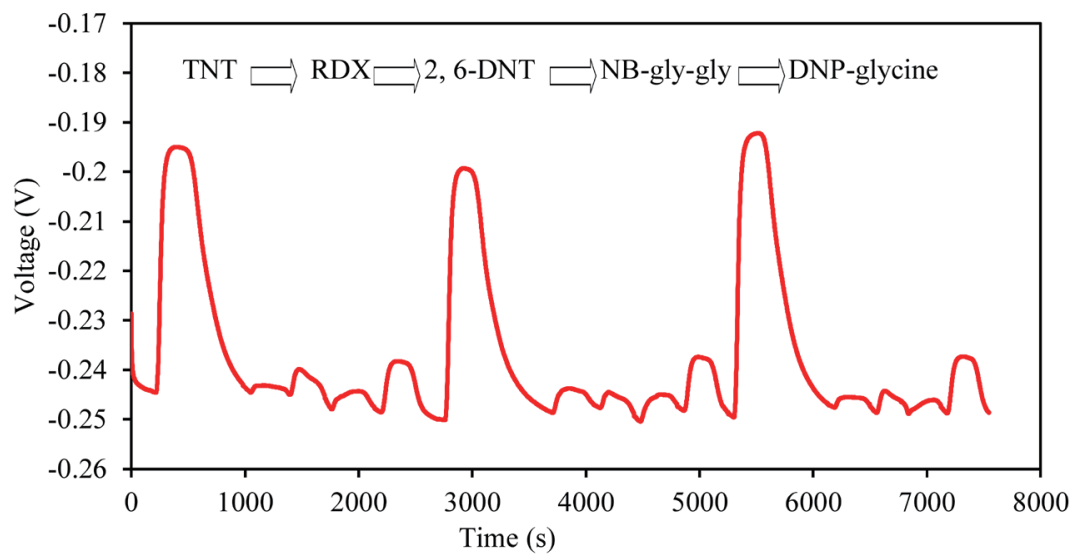

(a)

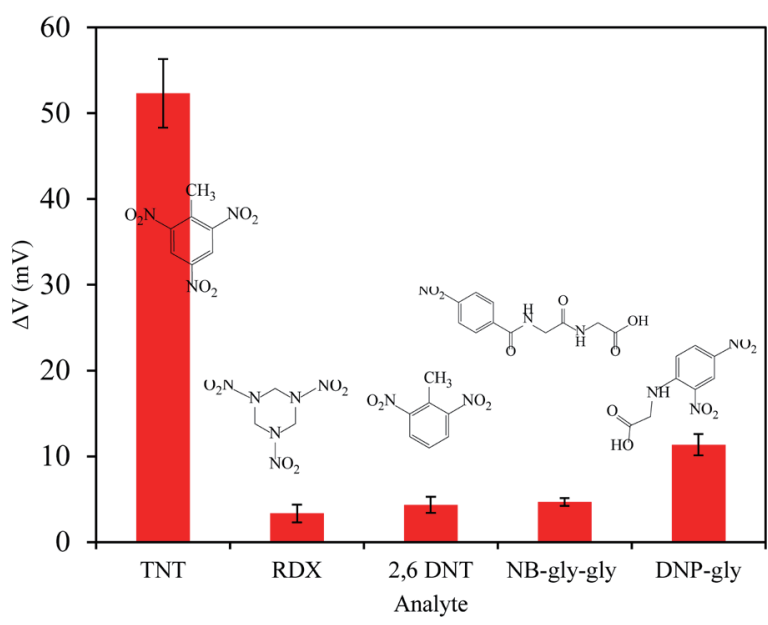

(b)

Fig. 4. (Color online) (a) Real-time sensorgram for TNT, RDX, 2.6-DNT, NB-gly-gly, and DNP-glycine at concentration of $501.5 \mathrm{ppm}$. (b) Selectivity of the TNTHCDR3-modified potentiometric device chip. Error bars indicate the calculated standard deviation $(n=3)$. 
enables strong interactions with the electron-rich amino groups of 3-aminopropyltriethoxysilane (APTES). This would result in the formation of a Meisenheimer complex because of the charge transfer from amino groups to aromatic rings. ${ }^{(23)}$ The TNT-binding peptide core amino sequence WHW was synthesized through the phage display method. ${ }^{(24,25)}$ In this study, the net charge of the TNT recognition peptide TNTHCDR3 (ARGYSSFIYWFFDFC) was negative because of the isoelectric point $(\mathrm{pI}=5.7)$ in the buffer solution $(\mathrm{pH} 7.4)$. On the basis of the above mechanism, the change in potential was mainly caused by the charge transfer between the positively charged group in the TNT molecule and the negatively charged peptide TNTHCDR3 when the TNT molecule and peptide interacted via the $\pi$ - $\pi$ interaction (WFY) and a hydrogen bond, which is illustrated in Fig. 1(e).

RDX, 2, 6-DNT, DNP-glycine, and NB-gly-gly have similar molecular structures to the TNT molecule. These four TNT analogues were used to investigate the selectivity of the rationally designed peptide. The TNTHCDR3 peptide-modified sensor exhibited a significant response to TNT and a background-level response to the four TNT analogues (Fig. 4), indicating the specific interaction between TNT and the peptide and hardly any nonspecific binding to the four TNT analogues. The stability of the peptide-based potentiometric device response was also investigated. Figure 5 shows the binding response for the same sensor chip over one week. The response to $125.4 \mathrm{ppm}$ TNT explosive was about $96.0 \%$ of the original value after 4 days and $77.9 \%$ after one week, indicating that the retention of the binding ability to TNT explosive was acceptable. The repeatability of the response of the peptide-based potentiometric device was calculated with a standard deviation of $0.85(n=5)$ at a TNT concentration of $31.4 \mathrm{ppm}$, which showed good repeatability of the sensor response.

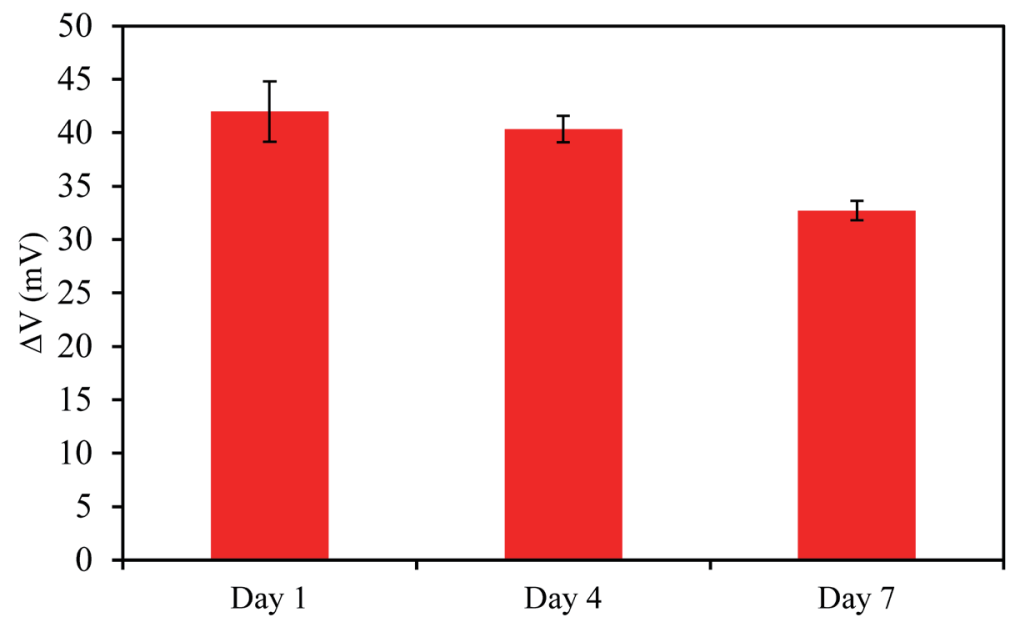

Fig. 5. (Color online) Stability of the sensor chip over one week (response to $125.4 \mathrm{ppm}$ TNT sample). 


\section{Conclusion}

We have demonstrated a TNT recognition peptide-functionalized potentiometric device for sensitive and highly selective TNT molecule detection in an aqueous solution. The LOD is expected to be improved to meet the need for the detection of ultralow-concentration traces of TNT in the future.

\section{Acknowledgments}

The authors appreciate the cooperation from Professors Miyahara, Goda, and Horiguchi from Tokyo Medical and Dental University who provided the potentiometric device and valuable advice. This work was supported by JST, the Miyada ImPACT Program under Grant HQJJ268702, Cabinet Office, Government of Japan.

\section{References}

1 X. Xuan, M. F. Hossain, and J. Y. Park: Sci. Rep. 6 (2016) 33125. https://doi.org/10.1038/srep33125

2 T. Minami, Y. Sasaki, T. Minamiki, S. Wakida, R. Kurita, O. Niwa, and S. Tokito: Biosens. Bioelectron. 81 (2016) 87. https://doi.org/10.1016/j.bios.2016.02.036

3 J. Fennell, H. Hamaguchi, B. Yoon, and T. Swager: Sensors 17 (2017) 982. https://doi.org/10.3390/s17050982

4 G. Xu, J. Abbott, L. Qin, K. Y. M. Yeung, Y. Song, H. Yoon, J. Kong, and D. Ham: Nat. Commun. 5 (2014) 4866. https://doi.org/10.1038/ncomms5866

5 Y. Ohno, K. Maehashi, and K. Matsumoto: J. Am. Chem. Soc. 132 (2010) 18012. https://doi.org/10.1021/ ja108127r

6 D. Kato, T. Kamata, D. Kato, H. Yanagisawa, and O. Niwa: Anal. Chem. 88 (2016) 2944. https://doi. org/10.1021/acs.analchem.6b00136

7 M. B. Pushkarsky, I. G. Dunayevskiy, M. Prasanna, A. G. Tsekoun, R. Go, and C. K. N. Patel: Proc. Natl. Acad. Sci. U.S.A. 103 (2006) 19630. https://doi.org/10.1073/pnas.0609789104

8 M. Cerruti, J. Jaworski, D. Raorane, C. Zueger, J. Varadarajan, C. Carraro, S. W. Lee, R. Maboudian, and A. Majumdar: Anal. Chem. 81 (2009) 4192. https://doi.org/10.1021/ac8019174

9 F. Zang, K. Gerasopoulos, X. Z. Fan, A. D. Brown, J. N. Culver, and R. Ghodssi: Chem. Commun. 50 (2014) 12977. https://doi.org/10.1039/C4CC06735E

10 Z. Kuang, S. N. Kim, W. J. Crookes-Goodson, B. L. Farmer, and R. R. Naik: ACS Nano 4 (2009) 452. https:// doi.org/10.1021/nn901365g

11 J. W. Oh, W. J. Chung, K. Heo, H. E. Jin, B. Y. Lee, E. Wang, C. Zueger, W. Wong, J. Meyer, C. Kim, S.-Y. Lee, W. G. Kim, M. Zemla, M. Auer, A. Hexemer, and S. W. Lee: Nat. Commun. 5 (2014) 3043. https://doi.org/10.1038/ ncomms 404

12 J. Wang, M. AlMakhaita, and S. L. Biswal: J. Biosens. Bioelectron. 3 (2012) 1. https://doi.org/10.4172/21556210.1000115

13 S. Hideshima, H. Hinou, D. Ebihara, R. Sato, S. Kuroiwa, T. Nakanishi, S. I. Nishimura, and T. Osaka: Anal. Chem. 85 (2013) 5641. https://doi.org/10.1021/ac401085c

14 T. Goda and Y. Miyahara: Biosens. Bioelectron. 45 (2013) 89. https://doi.org/10.1016/j.bios.2013.01.053

15 T. Goda, K. Masuno, J. Nishida, N. Kosaka, T. Ochiya, A. Matsumoto, and Y. Miyahara: Chem. Commun. 48 (2012) 11942. https://doi.org/10.1039/c2cc36111f

16 T. Goda, A. B. Singi, Y. Maeda, A. Matsumoto, M. Torimura, H. Aoki, and Y. Miyahara: Sensors 13 (2013) 2267. https://doi.org/10.3390/s130202267

17 Y. Horiguchi, T. Goda, A. Matsumoto, H. Takeuchi, S. Yamaoka, and Y. Miyahara: Biosens. Bioelectron. 92 (2017) 234. https://doi.org/10.1016/j.bios.2017.02.023

18 M. Okochi, M. Muto, K. Yanai, M. Tanaka, T. Onodera, J. Wang, H. Ueda, and K. Toko: ACS Comb. Sci. 19 (2017) 625. https://doi.org/10.1021/acscombsci.7b00035

19 J. Wang, M. Muto, R. Yatabe, Y. Tahara, T. Onodera, M. Tanaka, M. Okochi, and K. Toko: Sens. Actuators, B 264 (2018) 279. https://doi.org/10.1016/j.snb.2018.02.075 
20 Y. Mizuta, T. Onodera, P. Singh, K. Matsumoto, N. Miura, and K. Toko: Biosens. Bioelectron. 24 (2008) 191. https://doi.org/10.1016/j.bios.2008.03.042

21 T. Onodera, Y. Mizuta, K. Horikawa, P. Singh, K. Matsumoto, N. Miura, and K. Toko: Sens. Mater. 23 (2011) 39.

22 T. M. Swager: Electron. Noses Sens. Detect. Explos. 159 (2004) 29.

23 Y. Engel, R. Elnathan, A. Pevzner, G. Davidi, E. Flaxer, and F. Patolsky: Angew. Chem. Int. Ed. 49 (2010) 6830. https://doi.org/10.1002/anie.201000847

24 J. W. Jaworski, D. Raorane, J. H. Huh, A. Majumdar, and S. W. Lee: Langmuir 24 (2008) 4938. https://doi. org/10.1021/la7035289

25 S. K. Dower, P. Gettins, R. Jackson, R. A. Dwek, and D. Givol: Biochem. J. 169 (1978) 179.

26 D. Zhang, J. Jiang, J. Chen, Q. Zhang, Y. Lu, Y. Yao, S. Li, G. L. Liu, and Q. Liu: Biosens. Bioelectron. 70 (2015) 81. https://doi.org/10.1016/j.bios.2015.03.004

27 S. Z. Nergiz, N. Gandra, M. E. Farrell, L. Tian, P. M. Pellegrino, and S. Singamaneni: J. Mater. Chem. A 1 (2013) 6543. https://doi.org/10.1039/c3ta00138e

28 J. Wang, M. Muto, R. Yatabe, T. Onodera, M. Tanaka, M. Okochi, and K. Toko: Sensors 17 (2017) 2249. https://doi.org/10.3390/s17102249

29 J. Wang, S. Du, T. Onodera, R. Yatabe, M. Tanaka, M. Okochi, and K. Toko: Sensors 18 (2018) 4461. https:// doi.org/10.3390/s18124461 